\title{
METODOLOGIA DE PROJETO EM ARQUITETURA: DO OBJETO AO SUJEITO
}

\author{
Rogério Penna Quintanilha
}

Universidade de São Paulo - Faculdade de Arquitetura e Urbanismo - Pós Graduação. Universidade do Oeste Paulista (UNOESTE). E-mail: arq.rogerio@gmail.com

\section{RESUMO}

Os processos de concepção de um projeto arquitetônico envolve diversas etapas que nem sempre são claras, seja ao produtor-arquiteto, seja ao observador de sua obra. Este trabalho pretende contribuir para um pensamento epistemológico acerca dos mecanismos internos desses processos, incluindo a aproximação com as Belas Artes, o cientificismo modernista e a revisão contemporânea que procura questionar a possibilidade de uma criação arquitetônica puramente objetiva. Para tanto, utiliza-se dos três modos de raciocínio elencados pelo filósofo Charles Pierce - abdução, dedução e indução aplicados ao processo de projeto arquitetônico a partir das proposições de Eluiza Ghizi. Deste modo, a reflexão epistemológica acerca dos processos do característicos do conhecimento arquitetônico pretende contribuir para o domínio das ferramentas fundamentais destes campo, referenciando tanto futuras experiências de ensino de arquitetura como de prática profissional.

Palavras-Chave: Arquitetura, Urbanismo, Metodologia, Projeto, Desenho

\section{INTRODUÇÃO E OBJETIVO}

Os processos inerentes ao projeto de arquitetura são cercados de interpretações, discussões e subjetividade. Ciência aplicada, por um lado humana e artística, por outro objetiva e matemática, a arquitetura permanece como um meio de simultânea investigação e criação, o que a difere de outros campos de conhecimento. Ao arquiteto, não cabe apenas investigar ou interpretar a realidade, mas a de projetá-la e construí-la, um exercício que se não é absolutamente ausente em qualquer investigação científica (que também de alguma forma envolvem a construção da realidade), não constitui aqui uma característica velada e oculta, mas seu objetivo revelado.

O projeto de arquitetura tem sido interpretado, assim, de diversas maneiras ao longo do tempo. Durante o Renascimento, os projetos de embelezamento das cidades ou a ênfase compositiva das construções dava à arquitetura o status das artes superiores ou Belas Artes. O exercício do projeto arquitetônico, conforme descrito por Alberti, tornava-se um momento de criação intelectual, expressão artística baseada em grande arcabouço histórico e filosófico de referência clássica.

Após o século XVII, as tentativas de interpretação dos métodos de criação arquitetônicos como científicos tornam-se frequentes. A definição de Galileu Galilei de um método científico introduz uma rígida normatização dos processos de construção do conhecimento em diversas áreas das ciências naturais - por exemplo, astronomia e física - que se aproximam da arquitetura especialmente através 
da engenharia civil. Aos poucos, este método também é de alguma forma incorporado pelas ciências humanas e sociais, incluindo a arquitetura e o urbanismo. O auge deste urbanismo cientificista aconteceu em determinadas vertentes da arquitetura moderna, especialmente na primeira metade do século XX, sendo posteriormente criticado e revisto na segunda metade do século.

Dessa forma, esse artigo pretende discutir algumas características do método de projeto arquitetônico e suas possíveis aproximações com a metodologia científica das ciências naturais.

\section{METODOLOGIA}

A pesquisa foi desenvolvida através de revisão bibliográfica, como parte do Projeto de Pesquisa Docente (PPD) acerca dos métodos de projeto do arquiteto moderno brasileiro Joaquim Guedes. A partir desse entendimento teórico, foram observados e analisados relatos de experiências e pensamentos projetivos de diversos arquitetos, profissionais e estudantes, incluindo o próprio autor, em um processo que resultou em reflexões e sínteses entre essas experiências teóricas e práticas.

\section{RESULTADOS}

Os processos referentes ao desenvolvimento de projetos arquitetônicos são assunto freqüente nas discussões entre práticos e teóricos da arquitetura. Boa parte dessas discussões é epistemológica, ou seja, procura compreender os próprios processos da produção do conhecimento arquitetônico em sua dinâmica interna. Ao serem interrogados, não é difícil encontrar profissionais que, embora dominem empiricamente estes processos, pouco ou nada refletem sobre ele ou são capazes de traduzilo em palavras, o que costuma cercar o tema de algum ar de mistério e enigma característico das grandes inspirações do demiurgo.

Durante o Renascimento, tem suas características delimitadas pelos métodos projetivos de Brunelleschi e as diretrizes do tratado de Alberti. Estabelecida entre as Belas Artes, a arquitetura aproxima-se seus métodos de projetação dos modos da criação artística, da pintura, da escultura e do desenho em perspectiva, o mesmo valendo para o urbanismo.

Foi apenas no século XIX que, pelas mãos do espanhol Ildelfons Cerda, que o urbanismo estabeleceu-se como disciplina o mais possível relacionada aos processos científicos tradicionais das ciências naturais. O chamado método científico, desenvolvido por Galileu Galilei, caracteriza-se por relacionar a produção científica do conhecimento a uma metodologia definida que se inicia com a observação dos fenômenos da natureza, seguida da formulação de uma tese que o explique. A diferença é que, no método científico, esta tese deve ser verificada por um experimento cujo resultado deve 
predizer. Caso o resultado do experimento não seja o esperado, o cientista deve reformular sua tese a partir da nova observação. Se, ao contrário, o experimento confirmar a tese, uma nova lei é determinada e passa a compor o arcabouço do conhecimento científico. Nota-se aqui a inversão proposta por Galileu: enquanto na natureza, a lei precede o fenômeno, no conhecimento humano é a observação do fenômeno que precede a lei.

Se atualmente as próprias ciências da natureza já tem dificuldade em lidar com a rigidez do método científico, a questão se amplia determinantemente ao tratarmos de uma possível transposição desses métodos às ciências sociais, como a arquitetura. Baseada no modelo de construção acumulativo do conhecimento - como tijolos que se empilham na construção de uma catedral e que, um dia, hão de completá-la - o método de Galileu entra em crise juntamente com ele, substituído hoje por um modelo mais orgânico, interdependente e interdeterminante das diferentes etapas do progresso científico que passa a ser encarado mais como um progresso de algo do que rumo a algo.

No caso da arquitetura e do urbanismo, o modelo cientificista encontrou grande repercussão nas teorias de Le Corbusier, considerado um dos mestres da arquitetura moderna. Em primeiro lugar, as conhecidas metáforas mecanicistas tradicionalmente utilizadas pelo arquiteto - o avião, o navio, a casa como máquina de morar - demonstram a predisposição em fazer da arquitetura uma ciência baseada em princípios de racionalidade, funcionalidade e eficiência, em detrimento de subjetividades artísticas ou estéticas. Em segundo lugar, nota-se, especialmente nas teses desenvolvidas no livro Urbanismo, uma estrutura de raciocínio baseada no método científico tradicional, observação, tese e experimento, com o declarado objetivo de formular leis de urbanismo. O próprio livro é dividido em três partes que correspondem ao modelo de Galileu: diagnóstico - uma observação da situação das cidades - teoria teorização sobre os problemas urbanos e suas soluções - e experimento - proposta de aplicação dessas teorias urbanas em uma cidade real, em um plano conhecido como Plan Voisin para o centro de Paris.

Evidentemente, a não construção do Plan Voisin deixou o processo incompleto, já que o experimento não realizado não pode confirmar a tese que se propunha. De fato, a verificação empírica das teses propostas parece ter sido, ao longo do tempo, o principal empecilho tanto para Le Corbusier como para outros arquitetos que procuraram a mesma aproximação. Normalmente, depois de construído, o projeto não era mais visto como experimento capaz de aferir a veracidade da tese, e a culpa por seu não raro fracasso passou a ser distribuída entre vários agentes - alterações no projeto, erros de execução, incompreensão do cliente - de modo a proteger a integridade da tese que estava, por definição, correta e convertida em lei. Essa postura, evidentemente questionável, provoca diversos 
questionamentos sobre a validade desse tipo de transposição e sobre outras interpretações possíveis sobre a natureza da criação arquitetônica.

\section{DISCUSSÃO}

Uma das críticas ao modelo científico tradicional se encontra na discussão da possibilidade de qualquer raciocínio ser puramente objetivo e dedutivo, ou seja, sempre necessário a partir de premissas neutras e isentas de posicionamento e subjetividade. De fato, embora boa parte do fazer arquitetônico se baseie em deduções, a necessidade de uma premissa sempre anterior acaba por levar inevitavelmente a um dado original que é atribuído pelo arquiteto, ou seja, subjetivo e arbitrário. A atribuição desse dado original acaba por colocar em cheque o pretenso racionalismo e objetividade dos desdobramentos seguintes, uma vez que se baseiam em um dado conhecido a priori e, portanto, ideológico.

GHIZZI (2013) oferece uma alternativa a este modelo ao aplicar as formas de raciocínio elencadas pelo semiólogo, filósofo e matemático Charles Sanders Peirce: a abdução, a dedução e a indução. Basicamente, podemos entender a abdução como uma inferência a favor da melhor explicação que, no entanto, é contingente. Ou seja, observado um conjunto de dados $B$ que podem ser explicados por uma hipótese $A$, sendo $A$ a hipótese que melhor explica $B$, é provável (mas não necessário) que $A$ seja verdadeira. A dedução, por sua vez, é um argumento lógico que leva a uma conclusão necessária se as premissas forem verdadeiras (Todo homem é mortal/ Sócrates é homem/ logo, Sócrates é mortal). Finalmente, a indução é o argumento capaz de, por meio da experiência, comprovar ou refutar uma teoria deduzida, um raciocínio experimental. Assim, compreende que o processo de projeto arquitetônico inclui as três formas de raciocínio em diferentes etapas.

Em primeiro lugar, ao tomar contato com o problema arquitetônico - a necessidade de uma casa, por exemplo - o arquiteto formula por abdução uma primeira resposta que lhe parece provável ou que melhor pareça resolvê-lo. É importante notar que essa primeira resposta - partido arquitetônico - é contingente, ou seja, pode ou não ser verdadeira (e a experiência mostra que, em arquitetura, quase nunca é). No entanto, observamos que o papel desta etapa no processo arquitetônico não é a de propriamente fornecer uma resposta, mas a de proceder a seleção das premissas a partir das quais a segunda etapa dedutiva será estabelecida.

Note-se que, sem a seleção - e conseguinte restrição - das premissas, o raciocínio dedutivo é impossível ao arquiteto. Não se pode, normalmente, construir qualquer raciocínio dedutivo a partir de premissas infinitas, mas somente sobre um número limitado delas. Sendo o problema arquitetônico um 
problema do mundo real, seus dados iniciais de projeto são virtualmente infinitos. Ou seja, se um arquiteto se puser a analisar indefinidamente todos os fatores que condicionam o seu projeto, sejam seus aspectos físicos, sociais, econômicos ou de qualquer outra natureza, é provável que sua análise possa sempre ser ampliada e, ainda assim, ele jamais será capaz de conceber uma análise completa. Por outro lado, se é certo que não se pode encarar a etapa dedutiva do processo sem um número suficiente de premissas, também é certo que nem todas as possíveis análises serão realmente proveitosas à etapa seguinte, daí a importância da seleção. Em outras palavras, embora um arquiteto possa analisar indefinidamente um aspecto de seu problema arquitetônico - o terreno a ser implantado, por exemplo - é certo que nem todas as informações sobre ele serão igualmente relevantes, sendo algumas completamente dispensáveis para seu propósito. Pois, a primeira ideia, o partido arquitetônico desenvolvido por abdução a partir da situação real é aquela que identifica quais serão as premissas adotadas como mais relevantes, a partir de uma seleção que pareça melhor representar - ainda que reduzindo - a situação real.

Selecionadas as premissas, passa-se à etapa dedutiva do processo. Como visto, a dedução é uma forma de raciocínio necessária a partir de premissas que devem ser verdadeiras para que a conclusão também o seja. Dessa forma, o que difere as diferentes respostas ao mesmo problema arquitetônico os diferentes projetos - é a seleção inicial das premissas, destacando o caráter subjetivo de um processo que é, idealmente, objetivo. Do mesmo modo, GHIZZI (2006) destaca que o raciocínio dedutivo é também chamado de raciocínio diagramático, ou seja expressa-se através de diagramas - ou desenhos - que vão reduzir tanto o problema arquitetônico quanto a sua resolução aos seus aspectos considerados fundamentais.

É importante notar que o raciocínio dedutivo não se faz através da experiência do real, mas apenas a partir das premissas selecionadas que constituem tanto uma representação quanto uma redução. No entanto, se as premissas representarem suficientemente bem o problema arquitetônico real, o arquiteto terá condições de elaborar em sua imaginação uma resposta a eles, seguido do desenho de um esquema que, novamente, envolve uma nova elaboração da questão. A representação gráfica, ainda que esquemática, possibilitará uma melhor compreensão da representação do projeto arquitetônico, que levará a uma resolução mais definida e, novamente, a um desenho mais elaborado. Assim, sucessivamente, cada ciclo de observação, elaboração e representação do problema arquitetônico e sua solução conduz a uma resposta - ou projeto - mais bem elaborado, o que significa um aumento na qualidade do projeto arquitetônico produzido. 
Uma questão cotidiana tanto no ensino quanto na prática de projeto é a insatisfação com os resultados dessa etapa dedutiva. Por mais que o arquiteto, ou o acadêmico, elabore e reelabora seus desenhos, e o faça através de deduções racionais, a resposta parece satisfazer pouco ou nada o problema arquitetônico original. No entanto, compreendendo o processo epistemologicamente, podemos sugerir que, neste caso, não se trata de um raciocínio ou resposta ruim, uma vez que a resposta deduzida é necessária. O mais provável é que o problema esteja não no desenvolvimento do raciocínio, mas na seleção das premissas, ou seja, estando o processo dedutivo ocupado não do objeto real, mas de sua representação, uma representação ruim levará a todo um processo dedutivo insatisfatório. Neste caso, o projetista deve retomar a etapa inicial do processo, proceder uma nova abdução e, a partir de uma seleção mais apurada das premissas - e o fracasso na tentativa anterior contribui para isso - imaginar um novo partido arquitetônico que, embora permaneça contingente, tenha agora maior chance de ser verdadeiro.

Finalmente, se as etapas dedutivas do projeto se encaminharem satisfatoriamente, a arquitetura deve retomar o seu contato com o mundo real quando de sua construção. Neste momento, todas as informações - adotadas como premissas para a etapa dedutiva ou simplesmente apartadas do processo - se fazem presentes, exigindo novas adaptações no projeto. Isso acontece porque o projeto arquitetônico, mesmo que em nível executivo, se refere a uma representação do problema arquitetônico, e não à sua realidade.

\section{CONCLUSÃO}

Apresentados os argumentos, podemos concluir que os arquitetos modernos fracassaram em estabelecer uma arquitetura científica como verdadeira, real e excludente, exatamente porque todo o raciocínio dedutivo parte de premissas elencadas subjetivamente. Curiosamente, as próprias ciências da natureza também passaram a ter sua parcela de subjetividade considerada, abrindo inclusive o campo de revisão das leis já estabelecidas nas ciências naturais, o que na realidade se configura mais como um aprofundamento do que como uma negação. Sobre o projeto arquitetônico, é certo que possui desde o início uma diferença fundamental com estas, uma vez que as leis culturais e sociais, ao contrário das leis da natureza, são instáveis e em permanente mutação, não podendo ser reduzidas em axiomas estáveis. Finalmente, a aplicação das categorias de Peirce aos processos de projeto arquitetônico contribuíram para a flexibilização e para a maior compreensão dos movimentos internos destes, oferecendo novos olhares sobre essa prática tanto profissional quanto academicamente. 


\section{REFERÊNCIAS}

EINSEMAN, Peter. O Fim do Clássico: O fim do começo, o fim do fim. In: NESBITT, Kate. Uma Nova Agenda para a Arquitetura: Antologia teórica (1965-1995). São Paulo: Cosac Naify, 2008.

GHIZZI, Eluiza Bortolotto. Arquitetura em Diagramas: Uma Análise da Presença do Raciocínio DedutivoDiagramático no Processo Projetivo em Arquitetura. Cognitio-Estudos: Revista Eletrônica de Filosofia. Centro de Estudos do Pragmatismo - Programa de Estudos Pós-Graduados em Filosofia - Pontíficia Universidade Católica de São Paulo. v. 3. n. 2, p. 109 - 124. jul. dez. 2006. Disponível em <www.pucsp.br/pos/filosofia/Pragmatismo/cognitio_estudos/ cognitio_estudos.htm>. Acesso em 10 ago. 2013.

GUEDES Sobrinho, Joaquim. Um projeto e seus caminhos. Tese de Livre Docência - Faculdade de Arquitetura e Urbanismo da Universidade de São Paulo - FAUUSP, São Paulo, julho de 1981.

MOLES, Abraham A. A Criação Científica. São Paulo: Perspectiva, 1998. 3ạ Edição.

ROSSI, Paolo. O Passado, a Memória, o Esquecimento. Seis ensaios da historia das ideias. São Paulo: Unesp, 2010. 